\title{
Maternal and perinatal outcome in HELLP syndrome at VIMS, Ballari
}

\author{
Shiva Kumar HC Hiriyur Chidanandaiah, Prathiba M, Chandrashekhar T Tharihalli, \\ Suman Gaddi
}

\begin{abstract}
Correspondence: Shiva Kumar HC Hiriyur Chidanandaiah, Associate Professor, Department of Obstetrics and Gynaecology, Vijayanagara Institute of Medical Sciences, Bellary, Karnataka, India; Email- dr.hcshivkumar@gmail.com
\end{abstract}

Distributed under Creative Commons Attribution-Share Alike 4.0 International.

\begin{abstract}
Objective: The aim of this study was to ascertain the presentation, diagnosis, severity and complications of HELLP syndrome and evaluation of the maternal and fetal outcome. Methods: Pregnancy induced hypertension (PIH) between $1^{\text {st }}$ February 2016 and $31^{\text {st }}$ January 2017 was included in the study. Diagnosed cases of HELLP syndrome were classified according to Tennesses criteria after assessing inclusion and exclusion criteria. The analysis of the data was done on all the patients diagnosed with HELLP syndrome. Results: The incidence of HELLP syndrome during the period was $1.14 \%$ of total deliveries and $3.82 \%$ of pregnancy induced hypertension (PIH). Majority (50\%) patients belong to age group of 21 to 25 years. Mean age was 22.5 years. Most of them were primigravida (55\%). Majority $(52.5 \%)$ was in 36-40 weeks gestation and mean gestational age was 33.6 weeks. Head ache $(56.25 \%)$ was the most common imminent symptom. Most of symptoms were nonspecific like malaise $(50 \%)$, edema (45\%), vomiting $(20 \%)$ and epigastric pain $(7.5 \%)$. Out of 80 patients of HELLP syndrome 19 delivered by LSCS and 61 delivered vaginally. Ascites (26.25\%), PPH (25\%) and placental abruption $(22.5 \%)$ were the most common maternal complications in HELLP syndrome followed by acute renal failure $(18.75 \%)$, pulmonary edema $(12.5 \%)$, DIC $(6.25 \%)$ and cerebrovascular accidents $(6.25 \%)$. Maternal mortality in our study was $11.25 \%$. Perinatal mortality was $41.25 \%$. Conclusion: The reason for higher morbidity in our study is delay in identifying the problem by referring doctors. Earlier diagnosis and intervention improves maternal and perinatal outcome.
\end{abstract}

Keywords: HELLP, maternal mortality, perinatal mortality.

The HELLP syndrome is a serious complication in pregnancy characterized by hemolysis, elevated liver enzymes and low platelet count occurring in 0.5 to $0.9 \%$ of all pregnancies and in 10-20\% of cases with severe preeclampsia. The HELLP syndrome is a serious condition associated with substantial risk for the mother and her fetus. A wide range of complications may arise and the condition represents diagnostic and therapeutic problems; timing and method of delivery are important ${ }^{1}$.

The term HELLP syndrome was coined by Weinstein in 1982 and defined by the presence of all of the three following criteria: hemolysis (characteristic peripheral blood smear, serum lactate dehydrogenase $\geq 600 \mathrm{IU} / \mathrm{L}$, total serum bilirubin $\geq 1.2 \mathrm{mg} / \mathrm{ml}$ ), elevated liver enzymes

Received: $26^{\text {th }}$ November 2017. Accepted: $24^{\text {th }}$ January 2018 .

Chidanandaiah SK, Prathiba M, Tharihalli CT, Gaddi S. Maternal and perinatal outcome in HELLP syndrome at VIMS, Ballari. The New Indian Journal of OBGYN. 2018; 5(1): 18-23. 
(serum aspartate aminotransferase $\geq 70 \mathrm{IU} / \mathrm{l}$ ), and low platelet count $(<100,000 / 1)$. Partial HELLP syndrome (PHS) was defined by the presence of one or two features of HELLP, whereas in complete HELLP all three features are present ${ }^{2}$.

The diagnosis of HELLP syndrome may become very challenging because the patients may present with vague symptoms like nausea, vomiting, headache, malaise or flu-like symptoms. This leads to misdiagnosis of HELLP syndrome with various mild conditions like viral hepatitis to serious life-threatening conditions like acute fatty liver of pregnancy ${ }^{3}$. This study was undertaken with the objective to ascertain the presentation, diagnosis, severity, and complications of HELLP syndrome and evaluation the maternal and fetal outcome.

\section{Materials and methods}

After the approval of Institutional Ethical Committee and proper counseling and consent of the patients, this prospective observational study was conducted at Department of OBG, VIMS, Bellary in diagnosed cases of HELLP syndrome from $1^{\text {st }}$ February 2016 to $31^{\text {st }}$ January 2017. Diagnosed cases of HELLP syndrome were classified according to Tennesses criteria after assessing inclusion and exclusion criteria. Mainly women with eclampsia and severe pre-eclampsia were investigated. The analysis of the data was done on all the patients diagnosed with HELLP syndrome. Associated symptoms in the mother noted. Maternal morbidity in terms of pulmonary edema, ascites, acute renal failure, DIC, placental abruption, vision loss and maternal mortality noted. The perinatal outcome in terms of the IUFD, stillbirths, NICU admissions and early neonatal death were also noted.

Inclusion criteria

1. Women with HELLP syndrome using the Tennesses criteria

Criterias -

Complete HELLP Syndrome

- Platelet count $\leq 1,00,000 /$ cu.mm

- Serum $\mathrm{LDH} \geq 600 \mathrm{IU} / \mathrm{L}$

- Elevated liver enzyme - AST $\geq 70 \mathrm{IU} / \mathrm{L}$

Partial HELLP Syndrome - If one or two of the above criteria present.

2. Any gestational age

3. Puerperal cases were also included

\section{Exclusion Criteria}

1) Known case of hepatic disease, hemolytic anaemia,

2) platelet disorders.

2) Chronic hypertension in pregnancy.

3) Chronic renal diseases.

The clinical data included were value of pulse, blood pressure, respiratory rate and urine output. While the laboratory evaluations recorded were serial measurement of complete blood cell count, coagulation profile (PT, APTT), liver function tests (Serum bilirubin, ALT, AST, and $\mathrm{LDH}$ ), and renal function tests (Blood Urea, Serum Creatinine, and Serum Uric Acid). Disseminated intravascular coagulation (DIC) was diagnosed by presence of low platelets, prolonged PT and APTT, INR and D-dimer.

Abdominal ultrasonography was done when a subcapsular liver hematoma was suspected. Ophthalmoscopic examination was done in cases of severe pre-eclampsia and eclampsia. Magnesium Sulphate was used for seizure prevention and control. The diastolic BP was maintained between 90 and $100 \mathrm{~mm} \mathrm{Hg}$ using Labetalol (oral or parental) or Nifedepine (oral). Blood and blood products (FFP \& platelets) were used to correct coagulation abnormalities or anemia as needed. Antenatal steroid was given for fetal lung maturity if gestational age is less than 32 weeks. Fetal surveillance was done by modified Bio Physical Profile and Doppler. Decision to prolongation of pregnancy or termination was judged by duty doctor and Unit chiefs depending on maternal and fetal condition. Patients were managed in High Dependency Unit. Patients were shifted to ICU if mechanical ventilation was required or was hemodynamically unstable despite the treatment.

Statistical analysis data obtained was collected and analyzed statistically by proportions and tests of significance. Statistical significance was set at $p<0.05$.

Results

During the study period, there were a total of 6983 deliveries including 2094 women with PIH. A total of 80 cases of HELLP syndrome were diagnosed and managed. Incidence of HELLP syndrome was $1.14 \%$ of the total deliveries and $3.82 \%$ of the PIH patients. Severe Preeclampsia were $65(81.25 \%)$, eclampsia $10(12.5 \%)$ and normotensive were $5(6.25 \%)$ cases. In PIH patients 
Table1: Shows various maternal complaints in HELLP syndrome

\begin{tabular}{lllll}
\hline Complaints & $\begin{array}{l}\text { Complete } \\
\text { HELLP }\end{array}$ & $\begin{array}{l}\text { Partial } \\
\text { HELLP }\end{array}$ & No & Percentage \\
\hline Head ache & 25 & 20 & 45 & $56.25 \%$ \\
Malaise & 24 & 16 & 40 & $50 \%$ \\
Edema & 20 & 16 & 36 & $45 \%$ \\
Vomiting & 10 & 6 & 16 & $20 \%$ \\
Haematuria & 12 & 3 & 15 & $18.75 \%$ \\
Convulsions & 6 & 4 & 10 & $12.5 \%$ \\
Epigastric pain & 5 & 1 & 6 & $7.5 \%$ \\
Visual & & & & \\
Symptoms & 2 & 0 & 2 & $2.5 \%$ \\
\hline
\end{tabular}

45(2.14\%) were complete and 35(1.67\%) partial HELLP syndrome. Majority (91\%) was of lower socio-economic

Table 2: Admission parameters in our patients were divided according to Mississippi classification

\begin{tabular}{lcll}
\hline $\begin{array}{l}\text { Admission } \\
\text { Parameters }\end{array}$ & Class 1 & Class 2 & Class 3 \\
\hline $\begin{array}{l}\text { Platelet count }(/ \mu \mathrm{L}) \\
(\mathrm{Mean} \pm \mathrm{SD})\end{array}$ & $0.39 \pm 0.07$ & $0.88 \pm 0.21$ & $1.02 \pm 0.16$ \\
$\begin{array}{l}\mathrm{L} \text { (IU }(\mathrm{L}) \\
(\mathrm{Mean} \pm \mathrm{SD})\end{array}$ & $1665 \pm 655$ & $1011.17 \pm 422.4$ & $900.59 \pm 347.8$ \\
$\begin{array}{l}\text { AST }(\mathrm{IU} / \mathrm{L}) \\
(\mathrm{Mean} \pm \mathrm{SD})\end{array}$ & $468.4 \pm 68.3$ & $178.6 \pm 41.03$ & $169.24 \pm 69.3$ \\
\hline
\end{tabular}

status and was emergency admission (80\%). Nearly $2 / 3$ belonged to rural places. Fifty percent belong to age group of 21 to 25 years and twenty six percent to 18 to 20

\begin{tabular}{llll}
\multicolumn{4}{c}{ Table 3: Maternal complications in HELLP syndrome } \\
\hline Maternal & Complete & Partial & Total \\
Complications & HELLP & HELLP & \\
\hline Ascites & 15 & 6 & $21(26.25 \%)$ \\
PPH & 14 & 6 & $20(25 \%)$ \\
Placental abruption & 12 & 6 & $18(22.5 \%)$ \\
Acute Renal Failure & 12 & 3 & $15(18.75 \%)$ \\
Jaundice & 8 & 6 & $14(17.5 \%)$ \\
Pulmonary Edema & 6 & 4 & $10(12.5 \%)$ \\
DIC & 4 & 1 & $5(6.25 \%)$ \\
Intra Cranial Bleeding & 4 & 1 & $5(6.25 \%)$ \\
Sepsis & 3 & 1 & $4(5 \%)$ \\
Visual Disturbance & 2 & 0 & $2(2.5 \%)$ \\
Post Partum Collapse & 2 & 0 & $2(2.5 \%)$ \\
\hline
\end{tabular}

years. The mean age was 22.5 years. Primigravida were $44 \%$ and Gravida 2 were $25 \%$. Post partum cases were 3 $(3.75 \%)$. But, there is no statistical significance of maternal age and gravidity between complete and partial HELLP Syndrome $(\mathrm{P}=0.33)$.
Majority (52.5\%) of patients were between 36-40 weeks of gestation. Mean gestational age in this study is 33.6 weeks. Again, there is no statistical significance of gestational age among the different classes of HELLP syndrome $(\mathrm{P}=0.2333)$.

Out of total 80 patients of HELLP syndrome, 9 had spontaneous vaginal deliveries and 7 patients were taken for caesarian straight away. Remaining 64 patients were induced, out of these 52 delivered vaginally and 12 patients underwent emergency LSCS for various obstetric indications. Atonicity was the cause of post partum haemorrhage $(\mathrm{PPH})$ and majority were treated by uterotonics and two cases of PPH following LSCS were controlled by Bakri balloon (Table 3 ).

Acute renal failure (ARF) patients had gradual rise of renal parameters (blood urea and serum creatinine) for 7-14 days with oliguria followed by improvement in renal parameters in the $3^{\text {rd }}$ week. Initially these patients were managed using colloid plasma substitute with intravenous (IV) furosemide. They were monitored with serial renal function test (RFT) and serum electrolytes. If values persistently increasing, such patients were subjected to dialysis. In our study four number of ARF patients underwent dialysis and recovered (Table 3 ). Ten patients had pulmonary oedema, managed with oxygen, IV furosemide and ionotropes (dopamine or noradrenaline). All these patient required ventilator support, seven gradually recovered and three patient died. On ophthalmoscopic examination one case had retinal detachment and regained vision 24 hours after delivery. In other case, fundoscopy showed papilloedema, and gained vision over a period of one week. All Maternal complications were more in complete HELLP syndrome. But there was no statistical significance.

There were a total of $9(11.25 \%)$ maternal deaths. Most of them were complete HELLP syndrome. Eclampsia accounted for $7(77.77 \%)$ and severe preeclampsia for $2(22.22 \%)$ of maternal death. Pulmonary edema, DIC and cerebrovascular accident each accounted for $33.33 \%$ causes of maternal death. All these cases were 
Table 4: Perinatal outcome in HELLP syndrome

\begin{tabular}{lllll}
\hline $\begin{array}{l}\text { Perinatal } \\
\text { outcome }\end{array}$ & $\begin{array}{l}\text { Complete } \\
\text { HELLP }\end{array}$ & $\begin{array}{l}\text { Partial } \\
\text { HELLP }\end{array}$ & $\begin{array}{l}\text { Total } \\
\text { No (\%) }\end{array}$ & P Value \\
\hline IUD & 15 & 6 & $21(26.25 \%)$ & 0.421 \\
$\begin{array}{l}\text { Still Birth } \\
\text { Live Baby }\end{array}$ & 4 & 1 & $5(6.25 \%)$ & 0.352 \\
$\begin{array}{l}\text { Preterm } \\
\text { LBW }\end{array}$ & 16 & 32 & $\begin{array}{l}54(67.5 \%) \\
36(45 \%)\end{array}$ & 0.921 \\
$\begin{array}{l}\text { [Mean in Kgs] } \\
\text { NICU }\end{array}$ & 2.27 & 20 & 343 \\
$\begin{array}{l}\text { admission } \\
\begin{array}{l}\text { Early neonatal } \\
\text { death }\end{array}\end{array}$ & 22 & 8 & 2.38 & 0.167 \\
$\begin{array}{l}\text { Take home } \\
\text { baby }\end{array}$ & 5 & 2 & $7(8.75 \%)$ & 0.561 \\
\hline
\end{tabular}

maternal age was 21.4 yrs. Our study is in full agreement with Jayashree Mulik et $\mathrm{al}^{5}$.

Jayashree Mulik et $\mathrm{al}^{5}$ series most of the patients with HELLP were primigravida (85.2\%); which is a little higher than those reported by Ashwini Mallappasera et al ${ }^{3}(57.89 \%)$ and Campos $\mathrm{A}$ et al ${ }^{10}$ (64.3\%). In our study also most of patients with HELLP were primigravida (44\%).

Gasem et $\mathrm{al}^{7}$ and Gupta et $\mathrm{al}^{8}$ reported mean gestational age of 32.4 and 32.2 weeks. Jayashree Mulik et $\mathrm{al}^{5}$ reported maximum patients of gestation age between 33-36 wks (mean 34.6 weeks). This early presentation results in higher chances of prematurity. In our study majority were between 36-40 weeks of gestation. Mean gestational age was 31.5 weeks.

Headache, edema feet, puffiness of face, blurring of vision and abnormal weight gain were the major presenting symptoms in both HELLP and partial HELLP respectively. This finding is almost similar to all other studies ${ }^{3,4,5,6}$. Almost all the deranged lab test results reported by peers in other studies were corroborated with similar findings in our study ${ }^{3,4,5,6}$.

The nonspecific presentation of HELLP syndrome overlaps with a number of medical disorders. Therefore, the differential diagnosis of HELLP syndrome should include any of the conditions such as upper respiratory infection, hepatitis, cholecystitis, pancreatitis, acute fatty liver of pregnancy (AFLP), or immune thrombocytopenic purpura (ITP). In the absence of hypertension or proteinuria, these cases are misdiagnosed as having other conditions. Conversely, women with other conditions such as TTP, HUS, systemic lupus erythematosus, sepsis, or catastrophic antiphospholipid antibody syndrome may be erroneously diagnosed as having HELLP syndrome. Hence the most experienced clinician can face a difficult diagnostic challenge. Therefore, sincere efforts should be made to attempt to accurate diagnosis, so that management may be different among these conditions. It is important to emphasize that these patients have a variety of atypical signs and symptoms, none of which are diagnostic of severe preeclampsia. Hence, pregnant women with probable preeclampsia presenting with atypical symptoms should have a complete blood count, a platelet count, and liver enzyme determinations 
irrespective of maternal BP findings ${ }^{3}$.

Jayashree Mulik et $\mathrm{al}^{5}$ also reported increased rate of platelet and blood products transfusion in patient with HELLP syndrome. In our study more than $50 \%$ patients with HELLP and partial HELLP received blood transfusion. FFP was given to $55.55 \%$ patient of HELLP and $25 \%$ patients with partial HELLP. Our study is in full agreement with Gupta et $\mathrm{al}^{8}$. The early termination of pregnancy in HELLP syndrome was very high in several studies, including ours ${ }^{4,5,6}$. In most of studies ascites, pulmonary edema, placental abruption, PPH, DIC, ARF, cerebral haemorrhage, renal complications, and retinal detachment were seen. Our study is in full agreement with the study of Rekha Gurumurthy et al ${ }^{4}$, Jayashree Mulik et al and Sowjanya Kumari et $\mathrm{al}^{6}$ in maternal complications $4,5,6$.

Jayashree Mulik et $\mathrm{al}^{5}$ reported 3.8\%,Sowjanya Kumari et $\mathrm{al}^{6}$ reported $4.5 \%$ and Isler $\mathrm{CM}$ et $\mathrm{al}^{10}$ reported $7.8 \%$ of maternal mortality ${ }^{5,6,10}$. Cerebral haemorrhage, pulmonary edema, cardiac failure, renal failure and multi organ dysfunction were the cause of death in their series. In our study a total of $9(11.25 \%)$ maternal death occurred. In our study CVA, DIC and PPH equally contributed to maternal death. All cases were complete HELLP syndrome. All cases were referred from outside in a moribund status. High mortality in our series is because of delay in identifying the problem by referring doctors and late referral.

Sowjanya Kumari et $\mathrm{al}^{6}$ and Gupta $\mathrm{T}$ et $\mathrm{al}^{9}$ reported $13.53 \%$ and $16 \%$ IUD $^{6}$ where as in Rekha Gurumurthy et $\mathrm{al}^{4}$ series incidence of intra uterine death (IUD) was $33.3 \%$ which was high. Abruption was the cause in $88 \%$ of these IUD. In our study 21(26.25\%) were IUD and 5 were still birth. Abruption was associated with (12) $57.14 \%$ of IUD and $60 \%$ of still birth. Our study is comparable to Rekha Gurumurthy et al ${ }^{4}$.

Rekha Gurumurthy et al ${ }^{4}$ reported $16.6 \%$ early neonatal death due to sepsis, respiratory distress and birth asphyxia. Sowjanya Kumari et al ${ }^{6}$ reported $9 \%$ early neonatal death due to birth asphyxia and prematurity. In our study early neonatal death accounted for $8.75 \%$ similar to Sowjanya Kumari et al. Causes were birth asphyxia (28.5\%), intra ventricular hemorrhage (14.2\%), respiratory distress syndrome $(28.5 \%)$ and meconium aspiration syndrome (28.5\%).
The perinatal mortality in Sowjanya Kumari et $\mathrm{al}^{6}$ is $35.33 \%$ is comparable to our study i.e., $41.25 \%$. This high mortality is associated with preterm birth and its complications and abruption of placenta. These infants have high rates of respiratory distress syndrome, bronchopulmonary dysplasia, intracerebral hemorrhage and necrotizing enterocolitis. The reason for higher morbidity in our study is delay in identifying the problem by referring doctors. Most of the cases were referred to us at a late stage, biochemical changes identified HELLP syndrome and termination of pregnancy was planned upon admission to the hospital.

\section{Conclusion}

HELLP syndrome is associated with poor outcome for the mother and fetus. Nonspecific symptoms and signs results in miss diagnosis and inappropriate management. Anticipation of the problem and early identification of HELLP syndrome will reduce the complications. Definitive treatment for HELLP syndrome is delivery of the baby. Timely diagnosis and management of HELLP syndrome by induction and delivery by vaginal route or by cesarean section is beneficial and prevents complications in mother and fetus.

Early registration and regular ANC plays a major role in early diagnosis and to reduce complications like HELLP syndrome. Early detection, prompt referral, better transport facility, appropriate and timely intervention, availability of life saving facilities like mechanical ventilators, dialysis equipment and blood products like FFP, Platelets, Packed cell transfusion at tertiary care centers will significantly reduce the maternal and fetal morbidity and mortality. HELLP syndrome should be treated at tertiary care centers. The obstetricians at any level should be attentive, alert and need to improve quality care and make efforts for early identification even at its atypical presentation and provide skilled management techniques. Doctors should promote early and regular antenatal care at community health centers and ensure availability of new born care that will provide better maternal and perinatal outcome.

The global mortality rate of HELLP syndrome is very high. That's why it's critical for expecting mothers to be aware of the condition and its symptoms so that they can receive early diagnosis and treatment. Doctors should enhance their skills in antenatal care to identify the high 
risk factors at primary and tertiary care centers. This study uncovers only the tip of the iceberg as this is only a hospital based study. HELLP syndrome in non PIH cases was not evaluated.

\section{Acknowledgements}

We hereby would like to thank Dr. Suman Gaddi, Professor and HOD, Department of OBG; Dr. Sreenivasalu the superintendent of VIMS; Dr. Krishna Swamy, Director \& Principal VIMS, Bellary to allow us to publish this paper.

\section{Conflict of interest: None. Disclaimer: Nil.}

\section{References}

1.Haram K, Svendsen E, Abildgaard U. The HELLP syndrome: clinical issues and management. A Review. BMC pregnancy and childbirth. 2009. 26; 9(1): 1 .

2.Abbade JF, Pseraçoli JC, Costa RA, Calderon ID, Borges VT, Rudge MV. Partial HELLP Syndrome: maternal and perinatal outcome. Sao Paulo Medical Journal. 2002; 120(6): $180-4$.

3.Ashwini M, Srushti RK, Prashanth S, et al. A clinical study of HELLP syndrome and its outcome in a tertiary health care system .IJRCOG. 2016; 5(12): 4196-99.

4.Gurumurthy R, Gayathri KB, Sravanthi, Varsha S, et al. Clinical study of Maternal and Perinatal Outcome in Pregnancies Complicated by HELLP Syndrome. IOSR Journal of Dental and Medical Sciences. 2013; 9(2): 33-6.

5.Mulik J, Durugkar K, Agrawal N, et al. Clinical profile of Patients with HELLP and Partial HELLP Syndrome at a Tertiary care centre. GJRA - Global Journal for Research Analysis. 2016; 5(5): ISSN-2277 - 81605.
6.Kumari S, Bhavani, Himabindu, Lakshmi G, Madumitha M, et al. Clinical Study on HELLP Syndrome- Maternal and Perinatal Outcome. IOSR Journal of Dental and Medical Sciences (IOSR-JDMS). 2016;15(1): 71-6.

7.Gasem T, Al Jama FE, Burshaid S, Rahman J, Al Suleiman SA, Rahman MS. Maternal and fetal outcome of pregnancy complicated by HELLP syndrome. The Journal of MaternalFetal \& Neonatal Medicine. 2009 Dec 1; 22(12):1140-3.

8. Gupta T, Gupta N, Jain J, Gupta S, Bhatia P, Bagla J, et al. Maternal and perinatal outcome in patients with severe pre eclampsia/ eclampsia with and without HELLP syndrome. Journal of Universal College of Medical Sciences. 2013;1(4): 7-12.

9.Campos A, Goncalves A, Massa A, Amaral P, Silva P, Aguilar S, et al. HELLP Syndrome a severe form of preeclampsia: A comparative study of clinical and laboratorial parameters. Am J Exp Clin Res. 2016; 3(3): 170 -74 .

10.Isler CM, Rinehart BK, Terrone DA, Martin RW, Magann EF, Martin JN Jr. Maternal mortaility associated with HELLP Syndrome.American J obs Gyn.1999; 181(4): 924-8.

Shiva Kumar HC Hiriyur Chidanandaiah ${ }^{1}$, Prathiba $\mathbf{M}^{2}$, Chandrashekhar $T$ Tharihalli ${ }^{3}$, Suman Gaddi ${ }^{4}$

${ }^{1}$ Associate Professor, ${ }^{3}$ Professor, ${ }^{4}$ Professor \& HOD, Department of Obstetrics and Gynaecology, Vijayanagara Institute of Medical Sciences, Bellary, Karnataka, India; ${ }^{2}$ Senior Specialist, ESIMC \& RC, Bangalore. 